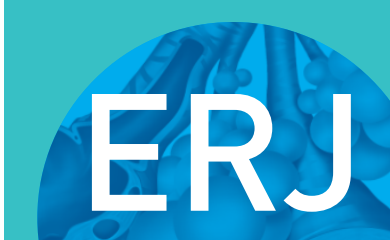

open research

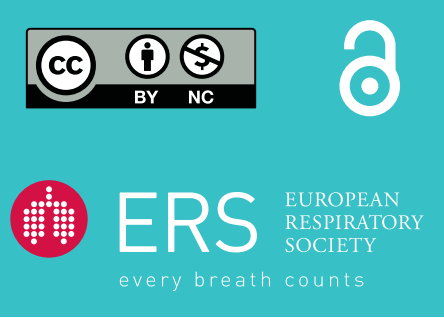

\section{Interaction of smoking with respiratory effects of occupational dust exposure: a prospective population study among Norwegian men}

\author{
To the Editor:
}

Occupational exposure to airborne pollutants increases the risk of respiratory symptoms and diseases among workers [1]. There is, however, a lack of prospective studies addressing the temporal relationship between airborne dust at work and respiratory symptoms in the general working population. Such studies permit the calculation of the population attributable fraction $[2,3]$. The attributable fraction of airborne pollutants at work to respiratory symptoms has not been estimated since 2003 [1]. As the labour market undergoes changes, there is a need for new prospective studies with updated estimates. We aimed to examine the prospective association between dust exposure and respiratory symptoms in the general working population of men. Further, we also aimed to examine if smoking is a possible effect modifier of the association between dust exposure and symptoms.

We used data from three subsequent waves (2006, 2009 and 2013) of the nationwide study of living conditions and work environment conducted by Statistics Norway (SN). Eligible respondents were men aged 18-66 years in 2006 that participated in at least two of the three panel waves, and who were employed in at least one of the panel periods $(n=3547)$. Statistics Norway collected data on exposure and outcome data by telephone surveys. Exposure to inhaled particles (metal, mineral and organic dust) was grouped into two categories (never/ever) based on the questions: "From where you work, can you clearly see in the air, or smell 1) ...mineral dust? e.g. from stone, quartz, cement, asbestos or mineral wool; 2) ...organic dust? e.g. from textiles, wood, flour, clothes or animals; and 3) ...dust or fumes from metals? e.g. welding fumes, or lead, chrome, nickel, zinc, aluminum, copper or tin dust". Duration of exposure was evaluated by dividing exposure-years into tertiles. Information on smoking habits, including daily smoking, was available for the periods 2009 and 2013. The outcome measure was respiratory symptoms during the last 4 weeks prior to the interview, reported at end of follow-up (2016), i.e. "Have you, over the past month, been severely afflicted by, somewhat afflicted, a little afflicted or not at all afflicted by chest tightness/wheezing in the chest?" Respondents who answered "yes" were defined as cases.

We computed odds ratios with $95 \%$ confidence intervals for respiratory symptoms in logistic regression models with adjustments for potential confounders using the computer package EGRET [4]. For the exposure to one, two or all three specified exposures, we calculated the population attributable risk per cent (PAR\%) with 95\% confidence intervals on the basis of the method described by NATARAJAN et al. [3]. The combined PAR\% was calculated according to the formula: 1 -(1 - PARvar1) $\times(1$ - PARvar2) $\times(1$ - PARvar3 $)$, etc. [2]. To evaluate if the effect of dust depends on daily smoking, we calculated the odds ratio for each stratum, relative to subjects with no exposure to smoking or dust (table 1), and calculated the expected additive joint effects using the equation: $O R(1,1)=O R(0,0)+(O R(1,0)-O R(0,0))+(O R(1,0)-O R(0,0))[5]$.

One out of four men reported exposure to airborne dust during follow-up (2003-2013). The prevalence of exposure was $18 \%$ at baseline and $11 \%$ at the end of follow-up. $6 \%(n=207)$ of the men reported

@ERSpublications

Dust at work is associated with risk of respiratory symptoms, the population attributable fraction is 19, and smoking is an effect modifier http://ow.ly/w0RF30jUL2Z

Cite this article as: Tynes T, Løvseth EK, Johannessen HA, et al. Interaction of smoking with respiratory effects of occupational dust exposure: a prospective population study among Norwegian men. ERJ Open Res 2018; 4: 00021-2018 [https://doi.org/10.1183/23120541.00021-2018]. 
TABLE 1 Risk of respiratory symptoms in 2013, all study subjects, and regressed on joint and separate effects of occupational dust exposure and daily smoking

\begin{tabular}{|c|c|c|c|}
\hline Exposure & All men" & $\begin{array}{l}\text { Daily smokers" } \\
\text { OR }(95 \% \mathrm{CI})\end{array}$ & $\begin{array}{c}\text { Nonsmokers } \\
\text { OR }(95 \% \text { CI) }\end{array}$ \\
\hline \multicolumn{4}{|c|}{ Mineral dust } \\
\hline Yes & $2.3(1.6-3.2)$ & $7.2(4.1-12.4)$ & $2.4(1.6-3.8)$ \\
\hline No & 1.0 & $3.5(2.4-5.1)$ & 1.0 \\
\hline \multicolumn{4}{|c|}{ Metal dust/fumes } \\
\hline Yes & $1.9(1.3-2.7)$ & $7.0(4.0-12.1)$ & $1.7(1.0-2.7)$ \\
\hline No & 1.0 & $3.3(2.2-4.8)$ & 1.0 \\
\hline \multicolumn{4}{|c|}{ Organic dust } \\
\hline Yes & $2.2(1.6-3.1)$ & $7.4(4.3-12.9)$ & $2.3(1.5-3.4)$ \\
\hline No & 1.0 & $3.5(2.4-5.2)$ & 1.0 \\
\hline \multicolumn{4}{|l|}{ Any dust } \\
\hline Yes & $2.1(1.6-2.8)$ & $7.2(4.6-11.3)$ & $1.9(1.3-2.8)$ \\
\hline No & 1.0 & $3.0(1.9-4.8)$ & 1.0 \\
\hline
\end{tabular}

respiratory symptoms in 2013. The prevalence of respiratory symptoms was more than three times higher in the population of daily smokers compared with nonsmokers (14.3\% versus $4.2 \%)$.

In the model adjusted for age and daily smoking, the risk of respiratory symptoms by exposure to any dust was $\mathrm{OR}=2.1$. Similar estimates were observed for mineral dust $(\mathrm{OR}=2.3)$, to metal dust/fumes $(\mathrm{OR}=1.9)$ and to organic dust $(\mathrm{OR}=2.2)$ (table 1$)$. Joint effects of exposure to any dust and daily smoking was more than additive, implying a multiplicative effect (the joint effect was 7.2 times, whereas it would be $1+(3.0-1)+(1.9-1)=3.9$ if the effects of the two factors were additive). Similar results were seen for the joint effect of smoking with the three classes of dust exposure analysed (table 1). Duration of exposure showed no increasing trend (not shown). The odds ratio of respiratory symptoms pertaining one or two exposures was 1.5 (95\% CI 1.0-2.2) and 1.5 (95\% CI 0.9-2.4), respectively. For all three exposures the odds ratio was 4.4 (95\% CI 2.5-7.7). The combined PAR\% for exposure to one, two or all three types of dust was 19. The PAR\% for exposure to any of the three specified types of dust was also 19 (95\% CI 7-32).

In this prospective study of chest tightness/wheezing among men in the general Norwegian working population, we found chest tightness/wheezing was associated with occupational exposure to dust in line with former prospective European/North American studies based on population samples [6-8]. Our finding of a more than four-fold increased risk of chest tightness/wheezing, when exposed to all three types of dust, may indicate that multiple exposures interact in causing airway pathology. Moreover, our finding of a PAR\% of 19 is in accordance with former population studies [1].

Our finding of an effect modification when comparing risk for respiratory symptoms in relation to the joint effect of daily smoking and dust has been previously reported, but not as consistently as in our data. A Dutch study also found that the effect of mineral dust on respiratory symptoms was modified by smoking [9]. Furthermore, two other studies reported similar results, but the excess risk was too small to conclude on effect modification [10,11]. Our results indicate a multiplicative effect, consistent with the hypothesis that dust exposure and smoking may biologically interact. The interaction suggests the possibility of impairment of lung clearing processes from cigarette smoke with subsequent increased susceptibility to dust particles, indicating the need for an increased focus on treatment of tobacco dependence in work-environment dust control policy.

This prospective population study, comprising three points of measurement over a 7-year period, was based on a large nationwide sample of men randomly drawn from the general Norwegian working-age population. Hence, we can assume good generalisability given that this study was not restricted to specific occupations or segments of the labour market.

A limitation of our study is self-reported smoking status, and it has been reported that self-reported dust exposure may be misclassified by disease status [6]. Self-report of chest tightness/wheezing, however, has been shown to be a good indicator of obstructive symptoms both for asthma and for chronic obstructive pulmonary disease patients $[12,13]$. To measure outcome only at the end of follow-up may, however, implies that men who experience respiratory symptoms due to dust exposure at work may have ended or reduced their exposure, either by finding a new job, by changing their job tasks during follow-up or in the 
worst case by retiring from work, leaving the healthy ones behind [14]. This fact, together with short exposure follow-up, may be the reason for not finding a significant increasing trend in our study.

In conclusion, we found a robust prospective association between exposure to dust at work and increased risk of respiratory symptoms in the general working population of men. Occupational exposure to dust accounted for about a fifth of the reported respiratory symptoms. Our findings imply that dust exposure is still a widespread problem in the work place, and that interventions should also strongly encourage treatment of tobacco dependence in smokers exposed to all types of dust at work.

\section{Tore Tynes $\oplus^{1}$, Eva Kristin Løvseth ${ }^{2}$, Håkon A. Johannessen ${ }^{2}$, Tom Sterud ${ }^{2}$ and Marit Skogstad ${ }^{3}$}

${ }^{1}$ National Institute of Occupational Health, Dept of National Surveillance System for Work Environment and Occupational Health, Oslo, Norway. ${ }^{2}$ National Institute of Occupational Health, Dept of National Surveillance System for Work Environment and Occupational Health, Oslo, Norway. ${ }^{3}$ National Institute of Occupational Health, Dept of Occupational Medicine and Epidemiology, Oslo, Norway.

Correspondence: Håkon A. Johannessen, National Institute of Occupational Health, Dept of National Surveillance System for Work Environment and Occupational Health, P.O. Box 8149 Dep, NO-0033 Oslo, Norway. E-mail: hajo@stami.no

Received: Feb 092018 | Accepted after revision: April 242018

Conflict of interest: None declared.

\section{References}

1 Balmes J, Becklake M, Blanc P, et al. American Thoracic Society Statement: occupational contribution to the burden of airway disease. Am J Respir Crit Care Med 2003; 167: 543-569.

2 Bruzzi P, Green SB, Byar DP, et al. Estimating the population attributable risk for multiple risk factors using case-control data. Am J Epidemiol 1985; 122: 904-914.

3 Natarajan S, Lipsitz SR, Rimm E. A simple method of determining confidence intervals for population attributable risk from complex surveys. Stat Med 2007; 26: 3229-3239.

4 EGRET for Windows Statistical Software. User Manual. Cambridge, CYTEL Software Corporation, 1988.

5 Rothman KJ, Greenland S, Lash TL. Modern Epidemiology. Philadelphia, Lippincott Williams \& Wilkins, 2008.

6 Bakke P, Eide GE, Hanoa R, et al. Occupational dust or gas exposure and prevalences of respiratory symptoms and asthma in a general population. Eur Respir J 1991; 4: 273-278.

7 Heederik D, Pouwels $\mathrm{H}$, Kromhout $\mathrm{H}$, et al. Chronic non-specific lung disease and occupational exposures estimated by means of a job exposure matrix: the Zutphen Study. Int J Epidemiol 1989; 18: 382-389.

8 Korn RJ, Dockery DW, Speizer FE, et al. Occupational exposures and chronic respiratory symptoms. A population-based study. Am Rev Respir Dis 1987; 136: 298-304.

9 de Meer G, Kerkhof M, Kromhout $\mathrm{H}$, et al. Interaction of atopy and smoking on respiratory effects of occupational dust exposure: a general population-based study. Environ Health 2004; 3: 6.

10 Sunyer J, Kogevinas M, Kromhout H, et al. Pulmonary ventilatory defects and occupational exposures in a population-based study in Spain. Spanish Group of the European Community Respiratory Health Survey. Am J Respir Crit Care Med 1998; 157: 512-517.

11 Zock JP, Sunyer J, Kogevinas M, et al. Occupation, chronic bronchitis, and lung function in young adults. An international study. Am J Respir Crit Care Med 2001; 163: 1572-1577.

12 Kart L, Akkoyunlu ME, Bayram M, et al. COPD: an underdiagnosed disease at hospital environment. Wien Klin Wochenschr 2014; 126: 73-78.

13 Vandenplas O, Ghezzo H, Munoz X, et al. What are the questionnaire items most useful in identifying subjects with occupational asthma? Eur Respir J 2005; 26: 1056-1063.

14 Pearce N, Checkoway H, Kriebel D. Bias in occupational epidemiology studies. Occup Environ Med 2007; 64: $562-568$. 